\title{
Publisher Correction: Macro and micro sleep architecture and cognitive performance in older adults
}

Ina Djonlagic D, Sara Mariani, Annette L. Fitzpatrick, Veerle M. G. T. H. Van Der Klei(D, Dayna A. Johnson, Alexis C. Wood, Teresa Seeman, Ha T. Nguyen, Michael J. Prerau, José A. Luchsinger, Joseph M. Dzierzewski, Stephen R. Rapp, Gregory J. Tranah, Kristine Yaffe, Katherine E. Burdick, Katie L. Stone, Susan Redline and Shaun M. Purcell iD

Correction to: Nature Human Behaviour https://doi.org/10.1038/s41562-020-00964-y, published online 16 November 2020.

In the version of this article initially published, labels in Fig. $2 \mathrm{~b}-\mathrm{e}$ and $5 \mathrm{~d}$ contained errors. The errors have been corrected in the PDF and HTML versions of this article. 
Original

a
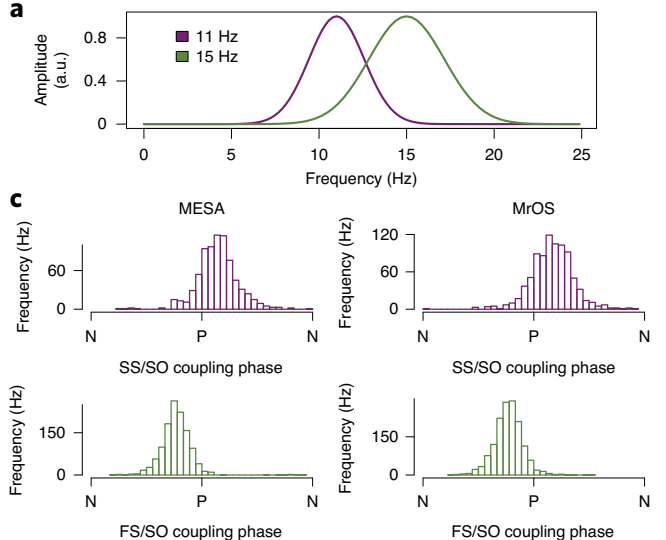

d 140 Age (years)
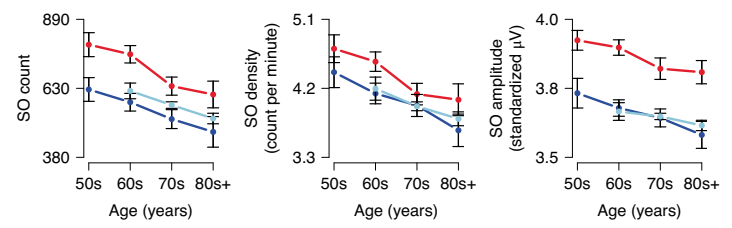
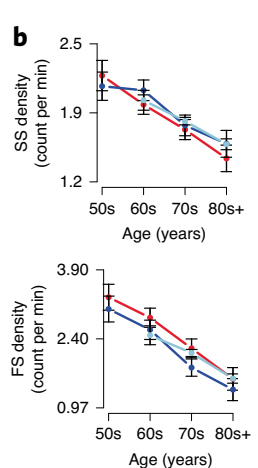

Age (years)
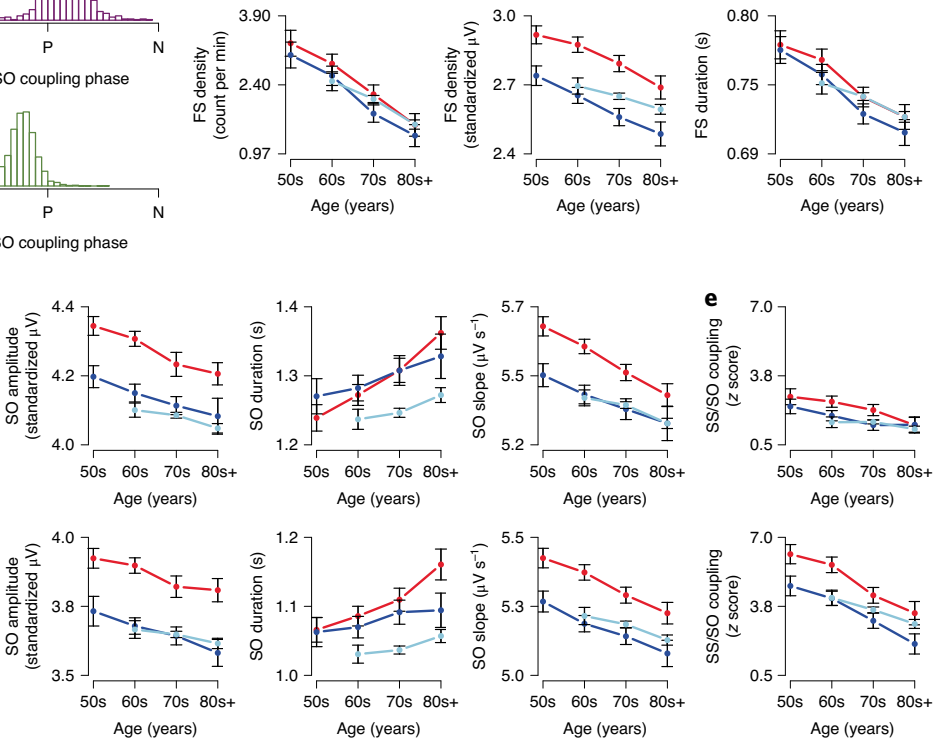

Age (years)

Age (years)
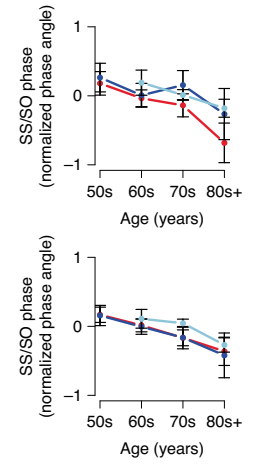

Corrected
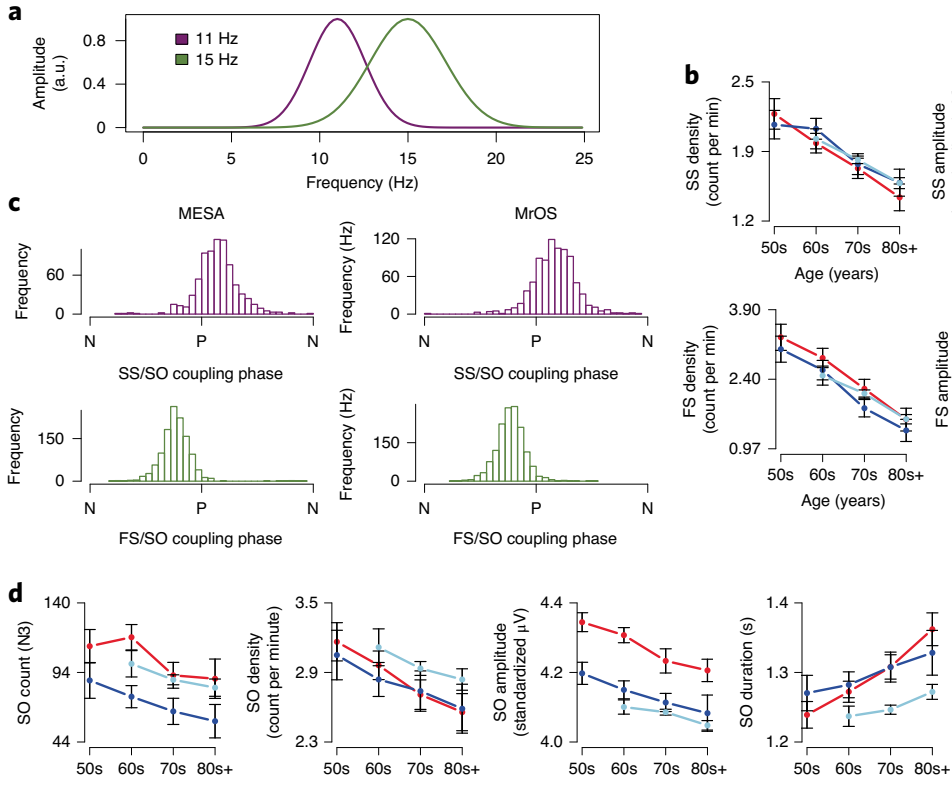

Age (years)

Age (years)
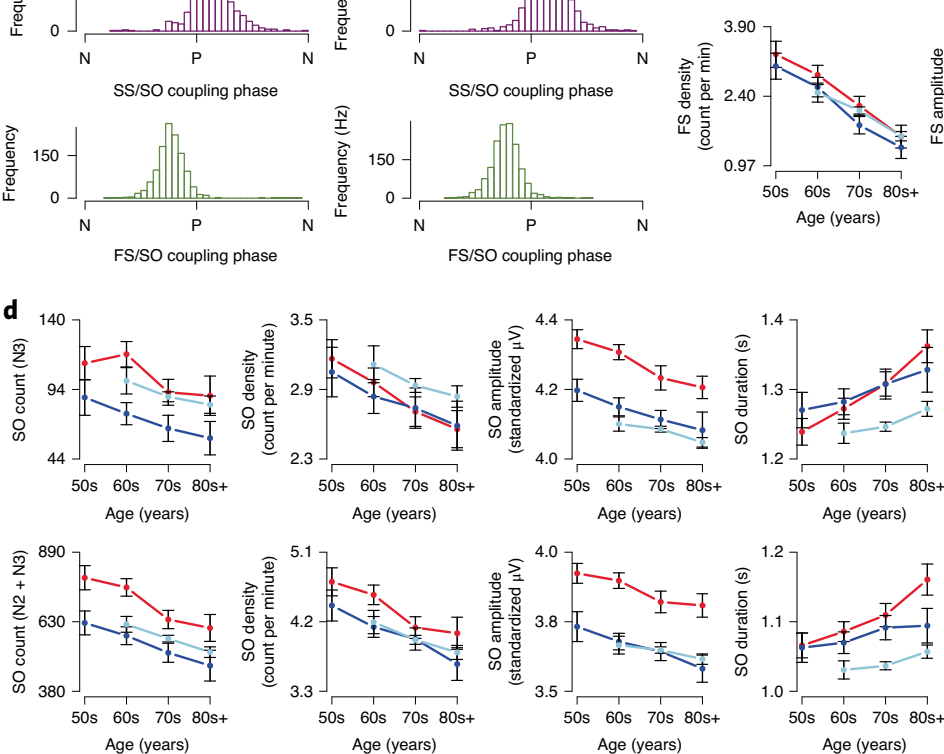
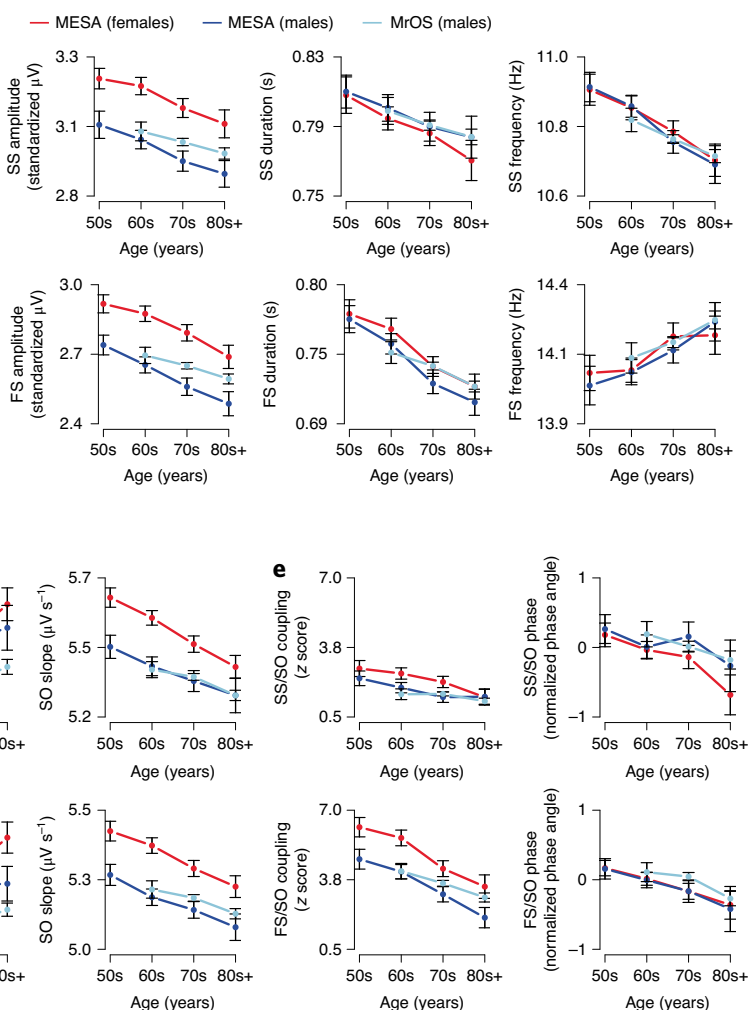

Fig. 2 | Original and Corrected. 
Original

d
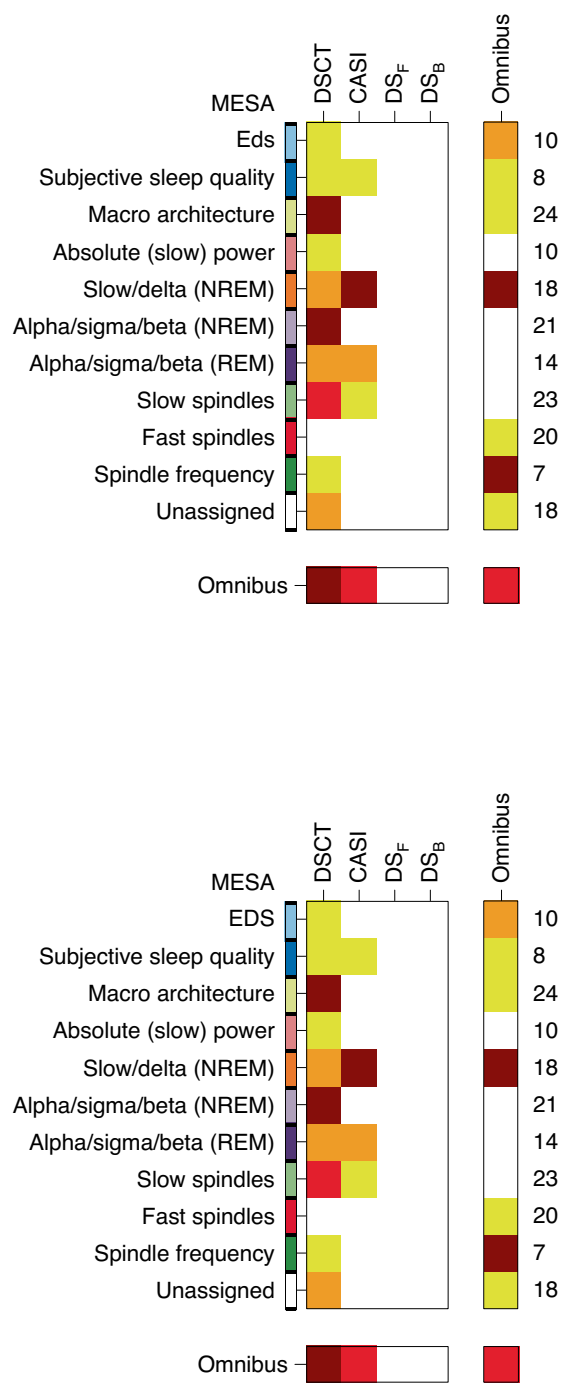

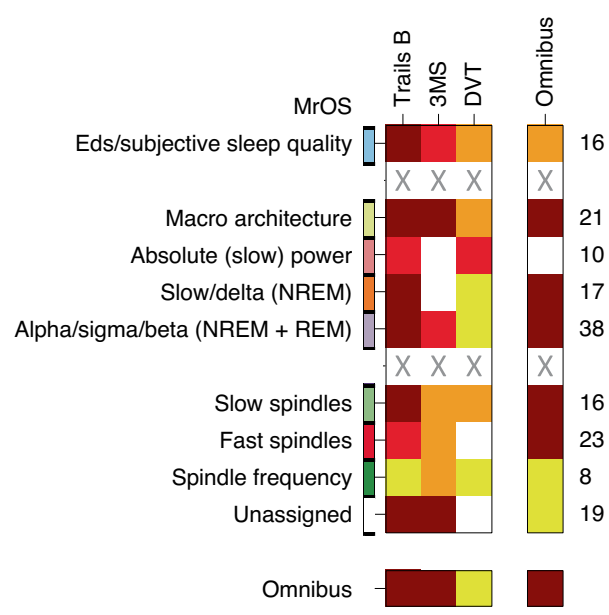

Corrected

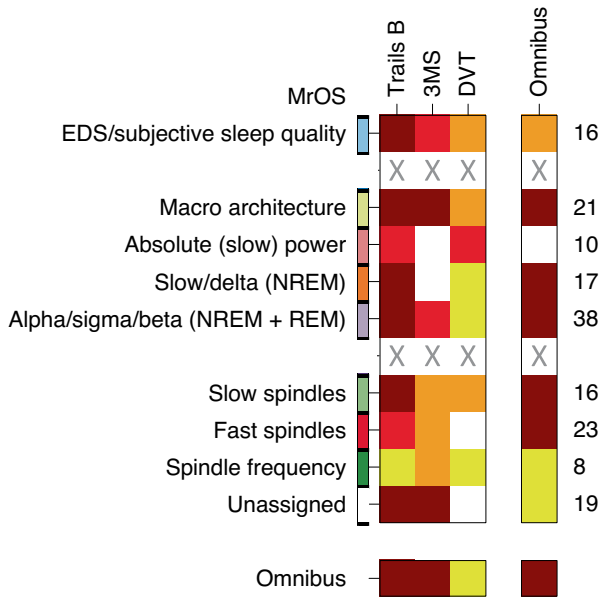

Fig. 5 | Original and Corrected.

Published online: 16 December 2020

https://doi.org/10.1038/s41562-020-01030-3

(C) The Author(s), under exclusive licence to Springer Nature Limited 2020 